AperTO - Archivio Istituzionale Open Access dell'Università di Torino

\begin{abstract}
Availability of emergency contraception: A survey of hospital emergency department gynaecologists and emergency physicians in Piedmont, Italy
\end{abstract}

This is the author's manuscript

Original Citation:

Availability:

This version is available http://hdl.handle.net/2318/125264

since

Published version:

DOI:10.3109/13625187.2012.692410

Terms of use:

Open Access

Anyone can freely access the full text of works made available as "Open Access". Works made available under a Creative Commons license can be used according to the terms and conditions of said license. Use of all other works requires consent of the right holder (author or publisher) if not exempted from copyright protection by the applicable law. 


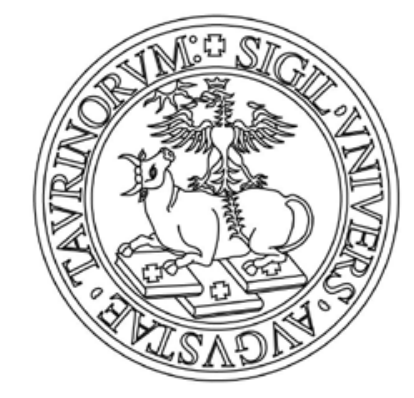

\section{UNIVERSITÀ DEGLI STUDI DI TORINO}

This is an author version of the contribution published on: European Journal of Contraception \& Reproductive Health Care Oct;17(5):373-82. 2012 doi: 10.3109/13625187.2012.692410

The definitive version is available at:[http://informahealthcare.com/doi/abs/10.3109/13625187.2012.692410] 


\title{
Availability of emergency contraception: A survey of hospital emergency department gynaecologists and emergency physicians in Piedmont, Italy
}

\author{
Marco Bo*, Ivo Casagranda ${ }^{\dagger}$, Lorena Charrier*\& Maria Michela Gianino* \\ *Department of Public Health, University of Turin, Italy \\ ${ }^{\dagger}$ Emergency Department, S.S. Antonio e Biagio e Cesare Arrigo Hospital Trust, Alessandria, \\ Piedmont , Italy
}

Correspondence: Marco Bo, MD, Department of Public Health, University of Turin, Via Santena 5 bis, 10126, Turin Italy.

Tel:+ 390116705840. Fax:+ 390116705881. E-mail: $\underline{\text { m.bo@unito.it }}$

\begin{abstract}
Objectives To compare the knowledge and the willingness of emergency physicians and gynaecologists caring for women in Italian emergency departments (EDs) to prescribe levonorgestrel-only emergency contraceptive pills (LNG-EC pills).

Methods A cross-sectional survey was conducted in 2009; anonymous postal questionnaires were mailed to the medical staff working at the 30 EDs located in Piedmont (Italy).

Results Emergency physicians and gynaecologists have similar knowledge of the pharmacokinetics and pharmacodynamics of LNG-EC pills, but do not feel at ease in prescribing these and consider the prescription of LNG-EC pills an inappropriate activity for ED staff.

Conclusions In Italy, unlike in most other European countries, LNG-EC pills are still prescription drugs. Thus it may be useful to further investigate the reasons why Italian ED medical staff do not feel the prescription of LNG-EC pills should be within their remit and whether women can successfully obtain the prescription from physicians working in other services that can be accessed around the clock.
\end{abstract}

Keywords:Emergency contraception,Emergency department,Gynaecologist,Emergency physician

\section{INTRODUCTION}

Emergency contraception (EC) refers to the use of drugs or intrauterine devices to prevent unwanted pregnancy after unprotected sexual intercourse. Systematic reviews have shown that EC pills are safe and associated with mild side effects such as nausea, vomiting, headache, dizziness, fatigue, breast 
tenderness, diarrhoea, and spotting or bleeding. Contrary to initial observations, EC pills significantly increase neither the risk of ectopic pregnancy ${ }^{1}$ nor that of harm to the developing embryo ${ }^{2}$.

In Italy levonorgestrel-only pills (LNG-EC pills) have been registered for EC since 2001. Initially marketed as two tablets of $750 \mu \mathrm{g}$, since 2011 they have only been available as one tablet of $1500 \mu \mathrm{g}$, as recommended by the World Health Organisation (WHO) ${ }^{3}$. According to a recent Cochrane systematic review, there are no significant differences in drug efficacy or in the incidence of side effects whether LNG-EC pills are administered in a single dose or according to a 12-hour split-dose regimen $^{1}$.

The efficacy of LNG-EC pills had been demonstrated up to 72 hours after unprotected coitus, but there was uncertainty about its effectiveness thereafter and whether or not its efficacy decreases with time since intercourse. A recent study combining data from four WHO randomised controlled trials concluded that it is still not established whether LNG-EC pills can protect against unintended pregnancy when administered on day five. At the same time it suggested that LNG-EC pills are effective up to 96 hours after unprotected sexual intercourse without evidence of a reduction in their efficacy up to this time interval. Nonetheless the authors suggested that LNG-EC pills should be administered as soon as possible after unprotected intercourse ${ }^{1,4,5}$.

It has been observed that women mostly ask for EC promptly, up to 24 hours after unprotected coitus, and that requests present an irregular trend, with peaks occurring during summer months (June to September), holidays (e.g., New Year's Day) and weekends (from Saturday to Monday) ${ }^{6-9}$.

These data give a plausible explanation why emergency departments (EDs) could be an important venue for EC prescription in countries where EC pills are only available with a medical prescription; this applies to Italy where they can be prescribed by any physician. In practice, however, during weekends or holidays the drug can be obtained only from physicians working at an ED or by physicians on out-of-hours duty - physicians who replace general practitioners in their activities during the nights, weekends and holidays. After having received a medical prescription, women have to go to a pharmacy that is also open out of hours, and buy the drug. In this context it is very important for women to find, as soon as possible, a physician working out of hours or an emergency physician willing to issue the prescription.

Numerous studies investigating ED medical staff's willingness to prescribe EC have shown that women find it difficult to obtain EC pills for a variety of reasons. Some investigators have cited the main reason for prescription refusal to be the fact that ED staff do not view unprotected sexual intercourse as a medical emergency or the provision of care needed in such situation as an appropriate activity for the $\mathrm{ED}^{10,11}$. To date, only a few studies have analysed medical staff's knowledge about the mechanism of action, efficacy and mode of proper administration of LNG-EC pills ${ }^{12}$.

For that reason we first carried out a survey to determine the frequency of requests of LNG-EC pills, the features of women asking for the drug, and the responses given by emergency physicians working at EDs in Piedmont ${ }^{13}$. We found that in the physicians' opinion the vast majority of requests came from Italian nationals (97\%) ranging in age from 18-30 years (76\%), single and not cohabiting with a partner (60\%), and nulliparous (64\%). Women mostly had not used LNG-EC pills before and the most common reasons for the request were condom breakage or slippage. Just over half the physicians stated that LNG-EC pills prescription was not an appropriate part of care provided at an ED, and most of 
them stated they felt uneasy about prescribing the drug. The vast majority of respondents stated they were willing to prescribe the drug if requested to do so, even if some of them believed that a physician could affirm his right to conscientious objection ${ }^{13}$.

This second study started from the observation that, in Piedmont, women seeking EC at an ED can be seen by an emergency physician or by a gynaecologist. The specialty of the physician who takes care of women depends on organisational choices independently decided in each hospital.

The aim of the present study was to compare opinions and behaviours reported in relation to LNG-EC pills prescription by gynaecologists to the ones expressed in our previous study by emergency physicians, and to compare the degree of knowledge about LNG EC pills' pharmacokinetics and pharmacodynamics between the two groups of professionals.

\section{METHODS}

A first cross-sectional survey was conducted in 2009 among 152 emergency physicians working in the 30 EDs in Piedmont (Italy). Twenty-four of these were first level EDs - EDs set in hospitals where a radiology unit, a laboratory and a blood transfusion service are accessible around the clock - while the six others were second level EDs - EDs set in hospitals which also have more specialised wards (e.g., Neurosurgery, Cardiac-, Thoracic- and Vascular Surgery). The first survey was followed a few months later by a second one, extended to 197 gynaecologists who may care for women requesting LNG-EC pills in the same EDs in Piedmont.

Postal questionnaires were mailed to each physician together with stamped, addressed envelopes in order for the completed questionnaires to be returned anonymously. The questionnaire had been validated before the first survey. The instrument design and corresponding references have been described elsewhere ${ }^{13}$. Here we analyse the answers given to 17 of the original 24 questions, which we consider most relevant to make a comparison between the two groups of professionals. The questions refer to six areas: (1) professional profile; (2) number and frequency distribution of LNG-EC pills prescription requests; (3) the physician's knowledge about LNG-EC pills pharmacokinetics; (4) the physician's knowledge about LNG-EC pills pharmacodynamics; (5) the physician's behaviour/opinions; and (6) the physician's role in the ED.

Approval was not sought from an ethics committee, because this is not required by law for anonymous postal questionnaire surveys in Italy. The questionnaires were accompanied by an information letter explaining the purpose of the study, the staff involved and a reminder that the completion of the questionnaires had to be done anonymously and that data obtained would be treated only in aggregate form.

\section{Statistical analysis}

Descriptive data are shown as absolute and relative frequencies of the different modalities for categorical data and as means \pm standard deviation (SD) for continuous variables. Student's t- test was applied to quantitative variables to compare the two study groups. 
Univariate analysis ( $\chi^{2}$ test or Fisher's exact test) was performed to verify if there was a statistically significant difference between the two groups in their knowledge about LNG-EC pills pharmacokinetics and pharmacodynamics, and in their personal behaviours and opinions.

Multivariate analysis was carried out using a logistic regression model to assess differences between the professional profiles of the two groups. The accuracy of response to the items was taken as the dependent variable; specialties (gynaecologist vs. emergency physician), gender, age, ED level (First vs. Second level ED), geographic location of the ED (regional or provincial capital vs. small town), requests for LNG-EC pills received in the previous year (yes vs. no) were considered as independent variables. For all tests the significance level was set at $\alpha=0.05$.

All analyses were performed using Stata software version 9.2.

\section{RESULTS}

Responses were returned by 53 gynaecologists (27\%) and 75 emergency physicians (49\%) working at Piedmont EDs (Table 1). There was no statistically significant difference between the two groups in relation to sex, age, or ED level. A significantly greater proportion of gynaecologists who responded, worked at an ED located in a regional or provincial capital whereas 51\% of emergency physicians who responded, worked at an ED located in a small town.

Emergency physicians were significantly more likely to have received a request for EC within the last year than were gynaecologists (Table 2). The absolute numbers of respondents varied, because while all the physicians who stated they had received some requests for EC prescription in the past year responded to the questions asked through the questionnaire - including the ones regarding their knowledge and their feelings - only some of those who stated they had received no requests responded to all the questions. Most physicians had not observed a seasonal trend in the requests, but they stated that they were more frequent at weekends (Table 2). Two thirds of emergency physicians reported that women had been refused a prescription by another service (Table 3).

ust over half of the respondents in either group considered LNG-EC pills prescription to be an inappropriate service for an ED. Just under half stated they felt uneasy with EC prescription. Nonetheless, virtually three quarters mentioned they were willing to prescribe the drug and to give women specific information on regular contraception when asked to prescribe LNG-EC pills (Table 3).

Whereas more than half believed that LNG-EC pills should always be prescribed when requested, a quarter believed that it is possible to exercise a right to conscientious objection under the Italian Code of Medical Ethics. As many as $21 \%$ of the gynaecologists and $14 \%$ of the emergency physicians thought that it is possible to exercise a right to conscientious objection under Italian legislation regulating voluntary abortion (Table 3).

There was no statistically significant difference between the two groups with regard to their knowledge of pharmacokinetics (Table 4). 
Most physicians in both groups stated that LNG-EC pills can be prescribed in more than one circumstance (Table 4). Very few chose only rape as a condition in which the drug should be prescribed, and only a small percentage in each group indicated the time criterion suggested by WHO a history of unprotected sexual intercourse in the 120 hours preceding the request - contrary to our expectation.

There were no statistically significant differences between the two groups with regard to their knowledge of pharmacodynamics of LNG-EC pills, except for the manner of taking the drug (Table 5).

While gynaecologists seem to think it makes no difference whether the pills are taken at once or at an interval of 12 hours of each other, more than a half of emergency physicians stated that both pills should be taken in a single dose $(\mathrm{p}=0.003)$. There was a statistically significant difference between the answers given by the two groups at univariate analysis, but this difference was not confirmed at multivariate analysis, after adjusting for gender, age, ED level, geographic location of the ED and requests for LNG-EC pills received (yes vs. no) in the previous year ( $p=0.138)$.

With regard to the knowledge of the mechanism of action of LNG-EC pills, the majority of respondents stated that they act through a complex mechanism of action involving inhibition of ovulation and fertilisation, alteration in tubal ciliary motility and sperm motility, and inhibition of implantation of the embryo; only $4 \%$ of gynaecologists correctly stated that the pill acts by inhibiting ovulation compared to $18 \%$ of emergency physicians. There was a statistically significant difference between the answers given by the two groups at univariate analysis, but this difference was not confirmed by multivariate analysis $(\mathrm{p}=0.093)$.

Both groups agreed with the statements that LNG-EC pills usually do not cause important side effects but can cause nausea, vomiting and headache, and that laboratory examinations before prescription are unnecessary.

Finally we also asked the participants what consequences may result from the use of LNG-EC pills. It was possible to give more than one answer. The most cited consequences were 'a decrease in voluntary abortions' and 'a decrease in unwanted pregnancies', followed by 'an increased risk of no longer using regular contraception', 'an increase in risky sexual behaviour and sexually transmitted infections (STIs)', and 'a greater chance of empowering women in relation to their reproductive health'.

\section{DISCUSSION}

This survey shows that emergency physicians and gynaecologists have similar knowledge of the pharmacokinetics and pharmacodynamics of LNG-EC pills. Unfortunately, the study has revealed that a significant proportion of them did not have a full knowledge of these aspects of the drug. In particular, many of them ascribed the pharmacological action of the pills to a multiple and complex mechanism of action, rather than only to the delay or inhibition of ovulation. A small but relevant number of them also stated that LNG-EC pills are abortifacients and that they act similarly to mifepristone. These data are a matter of concern, even if they come from a small sample, and further thought must be given to this problem. Because LNG-EC pills inhibit ovulation by a different mechanism than that characterising combined hormonal contraceptives, it is possible that the claim that the LNG-EC pills 
act by inhibiting ovulation like other contraceptives has not been considered a fully correct answer by some clinicians, causing some misunderstanding. Nonetheless the answers chosen by most of these professionals are inconsistent with the literature ${ }^{16-19}$. Their responses may be partly explained by an incomplete update, but confounding messages regarding the mechanism of action of LNG-EC pills released for years in Italy may also be a factor. The Italian Ministerial Decree authorising the sale of LNG-EC pills and the drugs' leaflets still state that LNG-EC pills can inhibit not only ovulation, but also embryo implantation. For that reason it has been stated for many years that LNG-EC pills had to be considered as abortifacients from a moral point of view ${ }^{20}$ : a statement recently renewed by the Italian National Committee on Bioethics despite clear evidence to the contrary.

We also found that some professionals considered a pregnancy test or blood coagulation tests to be necessary before the prescription of LNG-EC pills. This factor was independent of specialty and suggested that some professionals still overestimate the risk of side effects, and are overcautious in prescribing the drug.

It is also relevant that, even if most responding emergency physicians and gynaecologists were willing to prescribe the drug, many of them felt ill at ease about doing so and considered it an inappropriate activity for ED staff. This observation is in line with other previous studies ${ }^{10,13,14}$ and, in our opinion, several factors might be involved, such as the particular professional's moral views, and organisational aspects. Physicians may feel not at ease in prescribing the drug if they judge this to be immoral, but they may also experience discomfort, because they consider that going to an ED and asking for a prescription of EC pills is an inappropriate use of emergency resources and service. Indeed the prescription of EC pills does not usually need medical or laboratory examinations, and it may be more appropriately addressed by general practitioners and physicians of out-of-hours duty. Both these aspects could explain the findings of former inquiries that highlighted that doctors were less likely to prescribe EC pills to women asking for them after a voluntary unprotected intercourse than to victims of rape who need urgent medical assistance ${ }^{11,12,15}$. Unfortunately our study did not focus on this aspect and it did not allow us to further investigate the reasons for the feelings and opinions given by professionals.

\section{Strengths and limitations of the study}

This study has three main strengths. First of all it was conducted at Italian EDs, for which little information is on record. Second, it was conducted in a health system where women who go to an ED and ask for a prescription of LNG-EC pills can be seen either by emergency physicians or by gynaecologists, so that we could make a comparison between these two groups of professionals. Third, it examined the level of knowledge of the pharmacokinetic and pharmacodynamic characteristics of LNG-EC pills by ED medical staff, an aspect that other studies on record did not take into consideration $^{11,12,14,15}$.

At the same time, it has some important limitations. It was conducted through postal questionnaires and the response rate was low. This fact may have introduced a selection bias due to a possible higher response rate from physicians more sensitive to the issue addressed. Therefore the level of knowledge of physicians and their willingness to prescribe the drug could be overestimated. This is a particularly important aspect with regard to the answers provided by gynaecologists. Second, the reported data on the number and frequency distribution of the requests of LNG-EC pills can be in part subjective. Third, it was not possible to investigate in depth some important aspects, such as the reasons why many 
professionals feel uncomfortable in prescribing the drug and consider it an inappropriate activity for EDs’ medical staff.

\section{Relevance of the findings: Implications for clinicians and policymakers}

Our research shows that emergency physicians and gynaecologists have similar knowledge of LNG-EC pills and that they are willing to prescribe the drug. The data we gathered suggest that both emergency physicians and gynaecologists are familiar with LNG-EC pills and that women may be safely referred to either group to obtain a prescription for this product. Nonetheless the findings must be interpreted with caution due to the small sample size. Our study also supported the evidence that several physicians working at EDs do not consider the prescription of this drug an appropriate activity for ED staff, and that they feel uncomfortable in prescribing it.

\section{Future research}

The latter finding is relevant and it could be useful to further investigate in detail the reasons for those feelings through in-depth interviews that can better explore motivations and points of view.

At the same time it could also be useful to investigate whether women ask for prescription of LNG-EC pills from other services - such as physicians on out-of-hours duty or general practitioners - and if the latter are willing to issue the prescription. Even if in most European countries EC pills are available in pharmacies without medical prescription, they still can only be accessed by medical prescription in Italy. Moreover, unlike in France or in Sweden, in Italy EC pills cannot be issued by nurses or midwives, but only by physicians.

In this context, the recent authorisation of ulipristal acetate as an EC could only in part change the attitude of Italian ED medical staff towards EC pills prescription. The availability of ulipristal - which can be taken up to five days after unprotected intercourse - can theoretically increase the chance of women receiving EC on time, even when sexual intercourse takes place during the weekend or holidays. However, in Italy, ulipristal EC pills not only require a medical prescription but also a negative pregnancy test prior to prescription. Thus women may obtain the prescription easily only from services which usually provide such a test, like an ED, a gynaecologist or a family planning clinic. Ulipristal acetate might be more difficult to obtain from a general practitioner or a physician on out-of-hours duty, as they do not usually provide pregnancy tests in their surgeries.

\section{CONCLUSION}

This is the first study which compares the knowledge and feelings of emergency physicians and gynaecologists regarding the prescription of LNG-EC pills. It shows that the level of knowledge of the pharmacology of the drug is similar in the two groups of professionals, even if some relevant gaps still exist, in particular regarding the mechanisms of action of these pills. In line with previous observations it also shows that many emergency physicians and gynaecologists consider the prescription of LNG-EC pills an inappropriate activity for ED staff and that they do not feel at ease in performing it. 


\section{ACKNOWLEDGEMENTS}

The study was funded by the Piedmont Region (Piedmont Region Health Fund 2008).

Declaration of interest:The authors report no conflict of interest. The authors alone are responsible for the content and writing of the paper.

\section{REFERENCES}

1. Cheng L, Gülmezoglu AM, Piaggio G, .Interventions for emergency contraception. Cochrane Database Syst Rev 2008;(2):CD001324.

2. Trussell J, Ellertson C, Stewart F, .The role of emergency contraception. Am J Obstet Gynecol 2004; 190:S30-8.

3. UNDP, UNFPA, WHO, World Bank Special Programme of Research, Development and Research Training in Human Repoduction (HRP). Fact sheet on the safety of levonorgestrel-alone emergency contraceptive pills (LNG ECPs).Geneva: World Health Organisation 2010. Accessed January 2012 from:http://www.who.int/reproductivehealth/publications/family_planning/HRP_RHR_10_06

4. Faculty of Sexual and Reproductive Healthcare, Clinical Effectiveness Unit. Emergency contraception. 2011. Accessed January 2012 from:http://www.fsrh.org/pdfs/CEUguidanceEmergencyContraception11.pdf.

5. Piaggio G, Kapp N, von Hertzen H. Effect on pregnancy rates of the delay in the administration of levonorgestrel for emergency contraception: A combined analysis of four WHO trials. Contraception 2011; 84:35-9.

6. Aneblom G, Larsson M, von Essen L, Tydén T. Women's voices about emergency contraceptive pills ‘over- the-counter’: A Swedish perspective. Contraception 2002; 66:339-43.

7. Checa MA, Pascual J, Robles A, Carreras R. Trends in the use of emergency contraception: An epidemiological study in Barcelona, Spain (1994 - 2002). Contraception 2004;70:199-201.

8. Vergara Cano JC, López-Guerrero Almansa A, López López F. Anticoncepción de emergencia: Perfil de la usuaria en servicios de urgencias de atención primaria. Aten Primaria 2004;34:279-82.

9. Olszewski J, Olszewska H, Abacjew A, . The use of emergency contraception in young Polish women. Acta Obstet Gynecol Scand 2007;86:861-9.

10. Gbolade BA, Elstein M, Yates D. UK accident and emergency departments and emergency contraception: What do they think and do? J Accid Emerg Med 1999; 16:35-8.

11. Rosenberg KD, Demunter JK, Liu J. Emergency contraception in emergency departments in Oregon, 2003. Am J Public Health 2005;95:1453-7.

12. Harrison T. Availability of emergency contraception: A survey of hospital emergency department staff. Ann Emerg Med 2005;46:105-10.

13. Bo M, Casagranda I, Galzerano M, . Emergency contraception: a survey of hospital emergency departments’ staff. Emerg Care J 2011;7:10-5. 
14. Golden NH, Seigel WM, Fisher M, . Emergency contraception: pediatricians’ knowledge, attitudes, and opinions. Pediatrics 2001;107:287-92.

15. Espey E, Ogburn T, Leeman L, . Compliance with mandated emergency contraception in New Mexico emergency departments. J Womens’ Health (Larchmt) 2009;18:619-23.

16. Croxatto HB, Devoto L, Durand M, . Mechanism of action of hormonal preparations used for emergency contraception: A review of the literature. Contraception 2001;63:111-21.

17. Gemzell-Danielsson K, Marions L. Mechanisms of action of mifepristone and levonorgestrel when used for emergency contraception. Hum Reprod Update 2004;10:341-8.

18. Novikova N, Weisberg E, Stanczyk FZ, . Effectiveness of levonorgestrel emergency contraception given before or after ovulation - A pilot study. Contraception 2007;75:112-8.

19. Lalitkumar PG, Lalitkumar S, Meng CX, . Mifepristone, but not levonorgestrel, inhibits human blastocyst attachment to an in vitro endometrial three-dimensional cell culture model. Hum Reprod 2007; 22:3031-7.

20. Card RF. Conscientious objection and emergency contraception. Am J Bioeth 2007;7:8-14. 
Table 1 Personal data of responding physicians.

$\begin{array}{ccc}\text { Gynaecologists }(\mathbf{n}= & \begin{array}{c}\text { Emergency physicians }(\mathbf{n} \\ =\mathbf{7 5})\end{array} & \begin{array}{c}\text { p- } \\ \text { value }\end{array} \\ 24(46 \%) & 42(57 \%) & 0.241 \\ 42.6 \pm 9.6 & 44.2 \pm 7.4 & 0.311 \\ 30(63 \%) & 38(54 \%) & 0.375 \\ 40(82 \%) & 36(49 \%) & <0.001\end{array}$

Sex (Male, \%)

Age (mean \pm SD*)

Emergency Department, level (second level, \%)

Emergency Department, geographical location (regional or provincial capital, \%)

*SD, standard deviation. value

241

0.375

0.001

Table 2 Number and frequency distribution of prescription of levonorgestrel-only (LNG-EC) pills

$\begin{array}{lccc}\text { Number and frequency distribution of LNG- } & \text { Gynaecologists }(n=\text { Emergency physicians } \\ \text { EC prescription requests } & 53) & \begin{array}{c}\text { p- } \\ (n=75)\end{array} & \text { value }\end{array}$

How many requests for LNG-EC pills did you receive in the past year?

$1-20$

$36(68 \%)$

$12(23 \%)$

$4(8 \%)$

$1(2 \%)$

$0(0 \%)$

$>80$

Total of respondents

$53(100 \%)^{*}$

In which period of the year were requests most frequent?

Spring

$0(0 \%)$

$3(11 \%)$

$0(0 \%)$

$0(0 \%)$

24 (89\%)

$27(100 \%)$

Total of respondents

er was possible)

Monday

$0(0 \%)$

$0(0 \%)$

Tuesday to Friday

Weekend

Weekend and Monday

$21(96 \%)$

$0(0 \%)$

$0(0 \%)$

1 (5\%)

22 (100\%)*
$2(3 \%)$

0.000

$51(68 \%)$

18 (24\%)

4 (5\%)

$0(0 \%)$

$75(100 \%)$

$6(8 \%)$

$10(13 \%)$

2 (3\%)

$5(7 \%)$

52 (69\%)

75 (100\%)

2 (3\%)

2 (3\%)

55 (82\%)

1 (2\%)

$4(6 \%)$

$3(5 \%)$

$67(100 \%) *$
Total of respondents

*The sum of the reported percentages may not amount to $100 \%$ because of the rounding off. 


\section{Table 3 Physician's behaviour/attitudes and physician's role at the Emergency Department.}

Physician's behaviour/attitudes*

\section{Gynaecologists (n = 53)}

\section{Emergency p- physicians $(\mathbf{n}=$ value 75)}

Do you think that dispensing LNG-EC pills is appropriate for an Emergency Department?

\begin{tabular}{|c|c|c|c|}
\hline Yes & $24(47 \%)$ & $36(48 \%)$ & \\
\hline No & $27(53 \%)$ & $39(52 \%)$ & 0.917 \\
\hline Total of respondents & $51(100 \%)$ & $75(100 \%)$ & \\
\hline \multicolumn{4}{|l|}{ How comfortable do you feel about dispensing LNG-EC pills? } \\
\hline Very uncomfortable & $8(17 \%)$ & $16(22 \%)$ & \\
\hline Slightly uncomfortable & $12(25 \%)$ & $18(24 \%)$ & \\
\hline Fairly comfortable & $10(21 \%)$ & $20(27 \%)$ & 0.750 \\
\hline Very comfortable & $3(6 \%)$ & $4(5 \%)$ & \\
\hline Absolutely comfortable & $15(31 \%)$ & $16(22 \%)$ & \\
\hline Total of respondents & $48(100 \%)$ & $74(100 \%)$ & \\
\hline \multicolumn{4}{|l|}{ When asked to give a LNG-EC pill: } \\
\hline I prescribe it and give information about regular contraception & 32 (73\%) & $53(74 \%)$ & \\
\hline $\begin{array}{l}\text { I prescribe it but do not give information about regular } \\
\text { contraception }\end{array}$ & $2(5 \%)$ & $14(19 \%)$ & \\
\hline I refuse to give it and refer the woman to a gynaecologist instead & $9(21 \%)$ & $3(4 \%)$ & 0.000 \\
\hline $\begin{array}{l}\text { I refuse to give it and inform the woman that I have a conscientious } \\
\text { objection }\end{array}$ & $1(2 \%)$ & $2(3 \%)$ & \\
\hline Total of respondents & $44(100 \%)^{* *}$ & $72(100 \%)$ & \\
\hline \multicolumn{4}{|l|}{ Physician's role at the Emergency Department* } \\
\hline \multicolumn{4}{|l|}{ When asked to give a LNG-EC pill: } \\
\hline It should always be provided & $26(54 \%)$ & $43(60 \%)$ & \\
\hline $\begin{array}{l}\text { It may be offered in some circumstances but the Italian code of } \\
\text { Medical Ethics allows refusal due to conscientious objection }\end{array}$ & $12(25 \%)$ & $19(26 \%)$ & \\
\hline $\begin{array}{l}\text { It may be offered in some circumstances but Italian legislation } \\
\text { regulating voluntary abortion allows refusal due to conscientious } \\
\text { objection }\end{array}$ & $10(21 \%)$ & $10(14 \%)$ & 0.604 \\
\hline Total of responders & $48(100 \%)$ & 72 (100\%) & \\
\hline
\end{tabular}

Has it ever happened that one or more women arrived for care at the Emergency Department where you work and asked for a LNG-EC pill because they had been refused at another medical facility?

Yes

$13(30 \%)$

48 (66\%)

0.001

No

$31(70 \%)$

$25(34 \%)$

$44(100 \%)$

$73(100 \%)$

*The expected answer is indicated in bold.

**The sum of the reported percentages may not amount to $100 \%$ because of the rounding off.

LNG-EC pills, levonorgestrel-only EC pills. 
Table 4 Physician's knowledge about the levonorgestrel-only (LNG-EC) pill's pharmacokinetics

$\begin{array}{lcccc}\text { Physician's knowledge about } & \begin{array}{c}\text { Gynaecologists } \\ (\mathbf{n}=53)\end{array} & \begin{array}{c}\text { Emergency } \\ \text { physicians }(\mathbf{n}=\end{array} & \begin{array}{c}\text { Univariate } \\ \text { analysis } \mathbf{p}-\end{array} & \begin{array}{c}\text { Multivariate } \\ \text { analysis** }\end{array} \text { - } \\ \text { the LNG-EC pill's } & & 75) & \text { value } & \text { value }\end{array}$

In which of the following circumstances do you believe providing a LNG-EC pill is indicated?

$\begin{array}{lcc}\begin{array}{l}\text { Unprotected sexual intercourse in the } \\ 120 \text { hours preceding the request }\end{array} & 1(2 \%) & 5(7 \%) \\ \begin{array}{l}\text { Unprotected sexual intercourse during } \\ \text { the fertile period }\end{array} & 2(5 \%) & 7(9 \%) \\ \begin{array}{l}\text { Unprotected sexual intercourse with } \\ \text { subsequent risk of pregnancy }\end{array} & 8(18 \%) & 15(20 \%) \\ \text { Rape } & 2(5 \%) & 1(1 \%) \\ \text { All of the above } & 29(66 \%) & 42(56 \%) \\ \text { None of the above } & 2(5 \%) & 5(7 \%) \\ \text { Total of respondents } & 44(100 \%) * * * & 75(100 \%)\end{array}$

Within how many hours after intercourse should a LNG-EC pill be prescribed?

\begin{tabular}{|c|c|c|c|c|}
\hline $12-24$ & 7 (14\%) & 7 (9\%) & 0.864 & 0.056 \\
\hline 48 & $2(4 \%)$ & $18(24 \%)$ & & \\
\hline 72 & 34 (69\%) & 47 (63\%) & & \\
\hline 120 & 4 (8\%) & 3 (4\%) & & \\
\hline I don't know & $2(4 \%)$ & $0(0 \%)$ & & \\
\hline Total of respondents & $49(100 \%)^{* * *}$ & 75 (100\%) & & \\
\hline
\end{tabular}

*The expected answer is indicated in bold.

**Adjusted for gender, age, ED level, geographic location of the ED and requests for LNG-EC pills received (yes vs. no) in the previous year.

***The sum of the reported percentages may not amount to $100 \%$ because of the rounding off. 
Table 5 Physician's knowledge about the levonorgestrel-only (LNG-EC) pill's pharmacodynamics

$\begin{array}{lcccc}\begin{array}{l}\text { Physician's knowledge about the } \\ \text { LNG-EC pill's pharmacodynamics* }\end{array} & \begin{array}{c}\text { Gynaecologists } \\ (n=53)\end{array} & \left.\begin{array}{c}\text { Emergency } \\ \text { physicians }(n \\ (n)\end{array}\right) & \begin{array}{c}\text { Univariate } \\ \text { analysisp- } \\ \text { value }\end{array} & \begin{array}{c}\text { Multivariate } \\ \text { analysis p- } \\ \text { value** }\end{array}\end{array}$

Which is the more correct way of taking a LNG-EC pill?

The first pill must be taken at prescription and

15 (29\%)

$10(13 \%)$

0.003

0.138

the second 12 hours later

Both pills should be taken concurrently at

$13(26 \%)$

$39(52 \%)$

prescription

Both of the above

$\begin{array}{cc}14(28 \%) & 25(33 \%) \\ 9(18 \%) & 1(1 \%) \\ 51(100 \%)^{* * *} & 75(100 \%)^{* * *}\end{array}$

I don't know

Total of respondents

Does a LNG-EC pill cause major side effects?

Usually not, but it can cause nausea, vomiting and headache in some cases

$44(94 \%) \quad 72(96 \%) \quad 0.554 \quad 0.524$

Yes, severe metrorrhagia

$\begin{array}{ll}2(4 \%) & 2(3 \%) \\ 1(2 \%) & 0(0 \%)\end{array}$

Yes, fetal malformations if contraception ineffective

Yes, other effects

$0(0 \%)$

1 (1\%)

Total of respondents

47 (100\%)

75 (100\%)

Is it necessary to do laboratory examinations before prescribing a LNG-EC pill?

No

$\begin{array}{cc}37(77 \%) & 60(81 \%) \\ 4(9 \%) & 2(3 \%) \\ 6(13 \%) & 12(16 \%) \\ 1(2 \%) & 0(0 \%) \\ 48(100 \%)^{* * *} & 74(100 \%)\end{array}$

Yes, blood coagulation tests

Yes, a pregnancy test

\section{?}

Yes, for other reasons

Total of respondents

$2(4 \%)$

$41(84 \%)$

$13(18 \%)$

0.021

0.160

It acts through a complex mechanism of action involving inhibition of ovulation and fertilisation, alteration of tubal ciliary motility and sperm motility, inhibition of implantation of embryo

It acts through an abortive mechanism like that of mifepristone

Total of respondents

$\begin{array}{cc}6(12 \%) & 5(7 \%) \\ 49(100 \%) & 71(100 \%)\end{array}$

*The expected answer is indicated in bold.

**Adjusted for gender, age, ED level, geographic location of the ED and requests for LNG-EC pills received (yes vs. no) in the previous year.

$* * *$ The sum of the reported percentages may not amount to $100 \%$ because of the rounding off. 